RESEARCH NOTES

\title{
A NOTE ON GORDAN'S THEOREM OVER CONE DOMAINS
}

\author{
BRAD SKARPNESS \\ Department of Statistics \\ Virginia Polytechnical Institute \\ Blacksburg, Virginia 24061 \\ and \\ V.A. SPOSITO \\ Department of Statistics \\ Iowa State University \\ Ames, Iowa 50011
}

(Received April 6, 1982 and in revised form September 8, 1982)

ABSTRACT. This note presents a proof of Gordan's Theorem over general closed, convex cone domains which follows in a natural way appealing to the standard definitions of closed convex cones and their respective polar cones.

KEY WORDS AND PHRASES. Gordan's Theorem, closed convex cones, polar cones. 1980 MATHEMATICS SUBJECT CLASSIFICATION CODES. 90099.

\section{INTRODUCTION}

Solvability theorems or theorems of the alternative for problems involving linear system of equations has played a major role in mathematical programming, and linear analysis, (Craven [1], Luenberger [2] or Mangasarian [3]). Mangasarian [3] presents a rigorous development of the classical theorems of alternatives, see Chapter 2 in [3]. Many theoretical aspects in mathematical programming appeal to various theorems of the alternative in establishing certain optimality conditions and duality properties.

Ben-Israel [4], and Berman and Ben-Israel [5] extended the classical theorems of the alternative to problems with linear equations over polyhedral cone domains. Thus extending the classical formulations over nonnegative orthants as originally presented by Gordan [6]; i.e., problems involving a linear system over inequalities $(\geq 0)$. In particular, Ben-Israel proves a 
certain theorem, (Theorem 2 in [4]), which is utilized to establish extensions of the classical theorems of the alternative of Gordan, Motzkin, and Slater to problems formulated with linear equations over polyhedral convex cone domains. Ben-Israel underscores the fact that Theorem 2 cannot be used to generalize these results to general (nonpolyhedral) closed convex cones; see page 134 in [4]; hence, restricting the extension of the theorems of the alternative to problems involving general convex cone domains. Berman and Ben-Israel (cor. 1.5 in [5]), however, were able to establish a generalized Gordan's Theorem over general closed convex cone domain by appealing to Mazur's Theorem (Bourbaki [7]) or the Hahn-Banach Theorem (Schaefer [8]).

Craven (pg 31-33 in [1]), presents several theorems of the alternative over general closed .cone domains; however, a generalization of Gordan's Theorem is not explicitly given in this development. Therefore, the purpose of this note is to present a proof of Gordan's generalized theorem appealing only to the standard definitions of cones and their respective polar cones; hence, differing from the proof given by Berman and Ben-Israel in [5].

\section{ALTERNATIVE PROOF}

An alternative proof of Gordan's theorem over arbitrary convex cone domains is now presented over finite dimensional space. Consider the following definitions:

Definition 1. $C$ is a cone in $E^{n}$ if for any vector $y \varepsilon C$ and $k>0$ we have that ky $\varepsilon \mathrm{C}$.

Definition 2. A cone $\mathrm{C}$ is pointed if $\mathrm{C} \cap(-\mathrm{C})=\{0\}$.

Definition 3. $\mathrm{C}^{*}$ will denote the polar cone of an arbitrary cone $\mathrm{C}$ in $\mathrm{E}^{\mathrm{n}}$; that is

$$
\mathrm{C}^{*}=\left\{\mathrm{y}^{*} \varepsilon \mathrm{E}^{\mathrm{n}} \mid \mathrm{y}^{* \prime} \mathrm{y} \geq 0 \text { for a11 y } \varepsilon \text { C }\right\}
$$

Gordan's theorem over convex cone domains, Lemma 2 below, is established appealing to the following lemma: 
Lemma 1. Let $C$ be a closed convex cone in $E^{n}$. Then Int $\left(C^{*}\right) \neq \alpha$ iff $\mathrm{C}$ is a pointed cone.

Proof: Berman and Ben-Israel ([5], Lemma 0).

Lemma 2. (Gordan's Theorem for Arbitrary Cone Domains). Let $M$ be any given nonvacuous $m \times n$ matrix, with $C$ any arbitrary pointed, closed convex cone in $E^{n}$, then exactly one of the following systems is consistent;

(i) $M x=0$ for some $x \in C ; x \neq 0$

or

(ii) $M^{\prime} y \in \operatorname{Int}\left(-C^{*}\right), y \in E^{m}$.

Proof: (Not (ii) implies (i)).

Let $S_{1}=\left\{z \mid z=M^{\prime} y, y \varepsilon E^{m}\right\} ; S_{2}=\left\{z \mid z \varepsilon \operatorname{Int}\left(-C^{*}\right)\right\}$, then $S_{1} \cap S_{2}=\sigma$ and, moreover, $S_{1}$ and $S_{2}$ are convex sets. Since $S_{1}$ and $S_{2}$ are two disjoint convex sets in $\mathrm{E}^{\mathrm{n}}$, then there exists a hyperplane $\mathrm{v}$ (nonzero), such that

$v^{\prime} z_{1} \geq v^{\prime} z_{2}$ for all $z_{1} \varepsilon s_{1}$; for all $z_{2} \varepsilon \bar{s}_{2}$, (the closure of $s_{2}$ ). Hence,

$$
v^{\prime} M^{\prime} y \geq v^{\prime} z_{2} \quad \text { for all y } \varepsilon E^{m} ; \text { for all } z_{2} \varepsilon \bar{S}_{2}
$$

Assume $\mathrm{v} \notin \mathrm{C}$, then there exists $\mathrm{z}_{2}^{\star} \varepsilon \overline{\mathrm{S}}_{2}$ such that

$$
v^{\prime} z_{2}^{*}>0
$$

However, for any given $\mathrm{y}^{\star} \varepsilon \mathrm{E}^{\mathrm{m}}$, there exists $\overline{\mathrm{z}}_{2}^{*}=\mathrm{kz}_{2}^{*} \varepsilon \overline{\mathrm{S}}_{2}$, where $\mathrm{k}>0$, such that $v^{\prime} \bar{z}_{2}^{*}>v^{\prime} M^{\prime} y^{*}$, which violates $(2.2)$. Hence, it follows that $v \in C$.

Now letting $\bar{z}=0$, then $v^{\prime} M^{\prime} y \geq v^{\prime} \bar{z}=0$, hence, $v^{\prime} M^{\prime} y \geq 0$. However, letting $y=-M v$, we have that $-v^{\prime} M^{\prime} M v \geq 0$. Therefore, $M v=0, v \varepsilon C$ $(v \neq 0)$ hence, (i) holds.

To show now that (ii) implies not (i).

Let $y^{*}$ be such that $M^{\prime} y^{*} \varepsilon$ Int $\left(-C^{*}\right)$, and assume there exists $x^{*} \varepsilon C$ such that $\mathrm{Mx}^{*}=0 ; \mathrm{x}^{*} \neq 0$; then necessarily $\mathrm{y}^{*^{\prime}}\left(\mathrm{Mx}^{*}\right)=0$. A contradiction, since $M^{\prime} y^{*} \varepsilon \operatorname{Int}\left(-C^{*}\right)$ with $x^{*} \varepsilon C,\left(x^{*} \neq 0\right)$, implies that $x^{*^{\prime}}\left(M^{\prime} y^{*}\right)<0$. Hence, the result follows. 
3. CONCLUDING REMARKS

Lemma 2 requires that the cone $\mathrm{C}$ be closed, convex, and pointed; hence, by Lemma 1 Int $\left(-c^{*}\right) \neq \emptyset$. Clearly, relaxing this requirement could result in the inconsistency of both (i) and (ii) in Lemma 2.

\section{ACKNOWLEDGEMENTS}

The authors wish to thank the referees for many valuable and helpful suggestions.

\section{References}

1. CRAVEN, B. D. Mathematical Programming and Control Theory. Chapman and $\mathrm{Ha} 11,1978$.

2. LUENBERGER, D. G. Introduction to Linear and Nonlinear Programing. Addison-Wesley, Reading, Mass. 1973.

3. MANGASARIAN, 0. L. Nonlinear Programming. McGraw-Hill, New York, N.Y. 1969.

4. BEN-ISRAEL, A. Theorems of the alternative for complex linear inequalities. Israel Journal of Mathematics, 2, (1969), 129-136.

5. BERMAN, A. and BEN-ISRAEL, A. More on Linear inequalities with applications to matrix theory. Journal of Mathematical Analysis and Applications, 33, (1971), 482-496.

6. GORDAN, P. Üker die Auflösungen linearer Glerchungen mit reelen Coefficienten. Math. Ann., 6, (1873), 23-28.

7. BOURBAKI. N. Espaces vectoriels topologiques. Herman \& Cie, Paris. 1953.

8. SCHAEFER, H. Topological vector spaces. Macmillan, New York. 1966. 


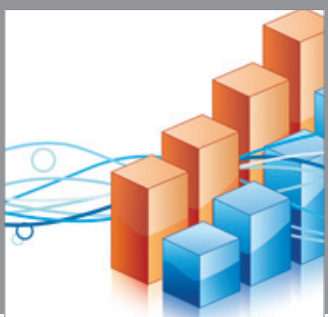

Advances in

Operations Research

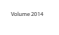

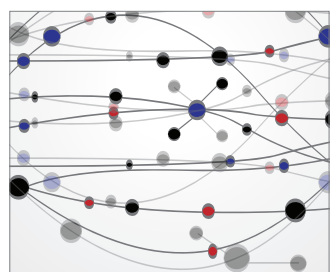

\section{The Scientific} World Journal
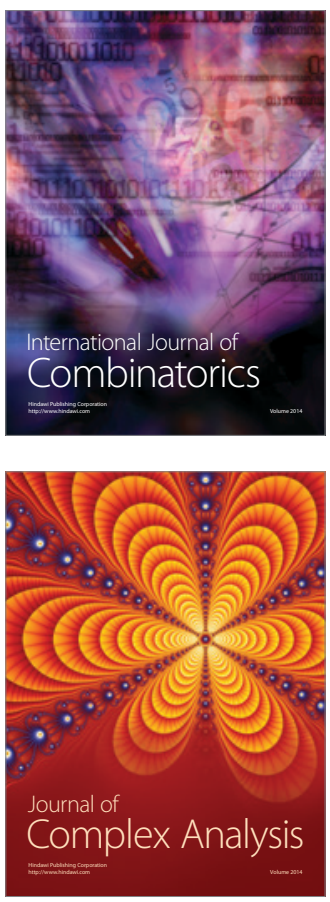

International Journal of

Mathematics and

Mathematical

Sciences
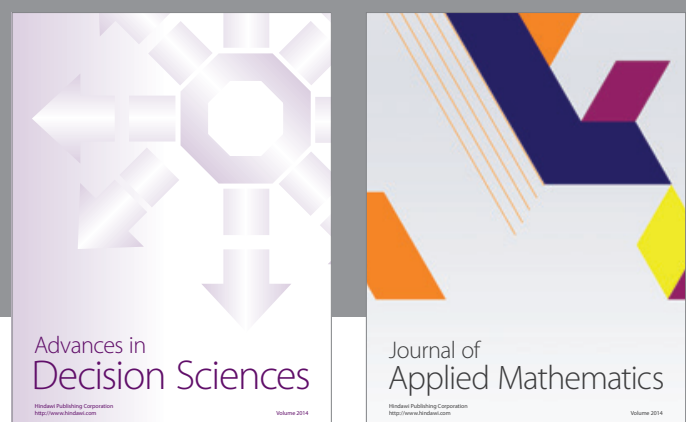

Journal of

Applied Mathematics
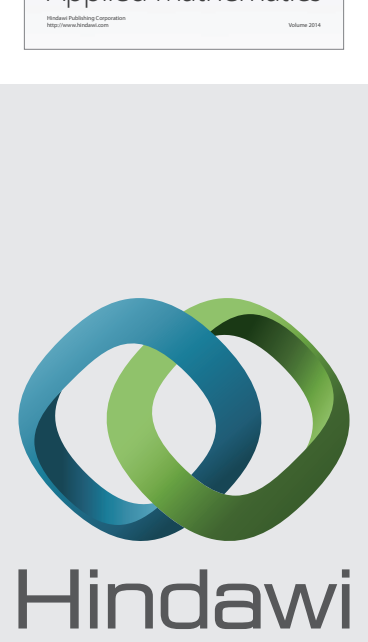

Submit your manuscripts at http://www.hindawi.com
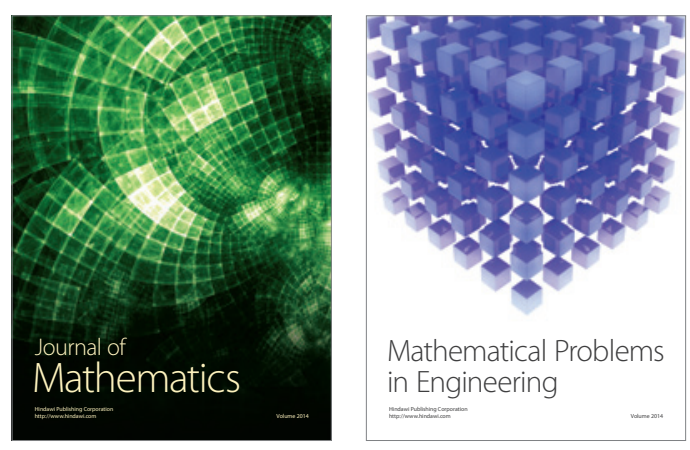

Mathematical Problems in Engineering
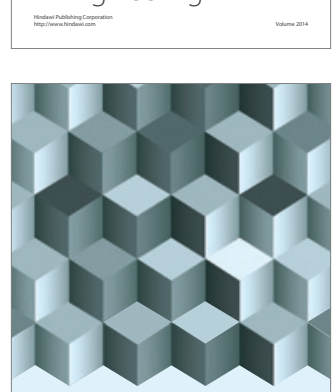

Journal of

Function Spaces
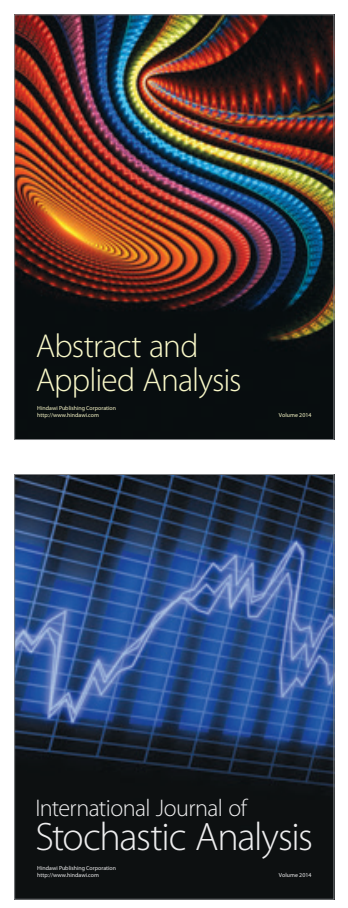

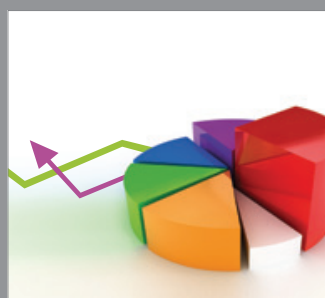

ournal of

Probability and Statistics

Promensencen
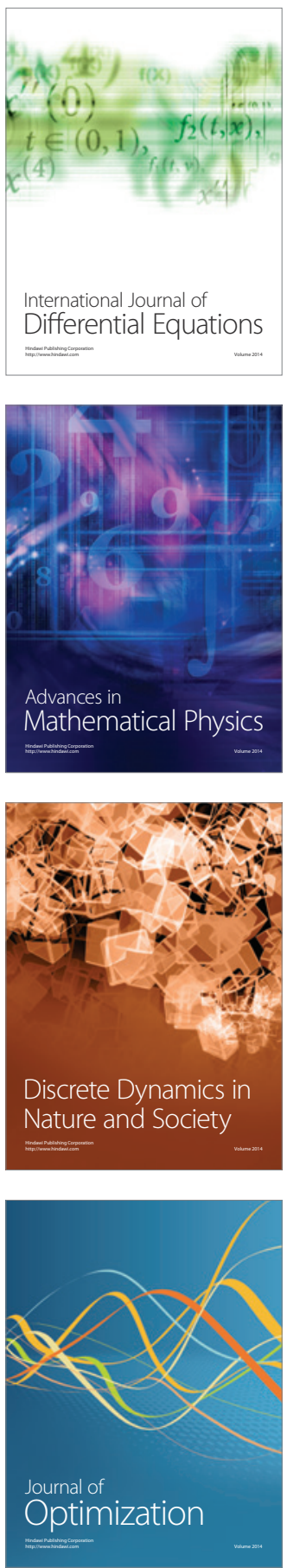